\title{
CORPORATES MAKE RELUCTANT PARTNERS
}

\author{
The Japanese government wants to lure more \\ industry funding into universities, but companies \\ need to be convinced they'll get value.
}

BY ICHIKO FUYUNO

$\tau$ apanese brands are recognized globally for their manufacturing and engineering sophistication. The companies that built them, from Toyota to Sony, don't just drive the national economy, they also boost research and development.

Japanese corporations are a dominant force in the Nature Index. They were the secondlargest contributors after the United States to the share of corporate authorship between 2012 and 2016. Their output accounted for $3.34 \%$ of Japan's total index contribution, outweighing the corporate share in the US, South Korea, and China.

Yet despite their strong publication performance, Japanese companies acknowledge that their scientific activities are primarily motivated by the desire to capture emerging markets before their competitors.

Corporations in Japan have also been reluctant to partner with local universities. They are discouraged by the lengthy administrative process involved in finalizing contracts, and what they see as a lax attitude of researchers to commitments and deadlines. But, with the government increasingly recognizing corporations as an important partner for academia, the relationship might soon grow closer.

"We hope a series of government-supported initiatives will lure more corporate funding into universities," says Takashi Uchino, unit chief of the University-Industry Collaboration and Regional R\&D Division at the Ministry of Education, Culture, Sports, Science and Technology (MEXT).

\section{IN BUSINESS}

Japan's economy took a drastic hit from the 2008 global financial crisis and was further compromised by the 2011 earthquake. Recovery has been slow, and with growing social and welfare expenses, universities have suffered. Government funding for basic university operating budgets has steadily declined to 1,097 billion yen (US $\$ 10$ billion) in 2016, down $11 \%$ from 2004.
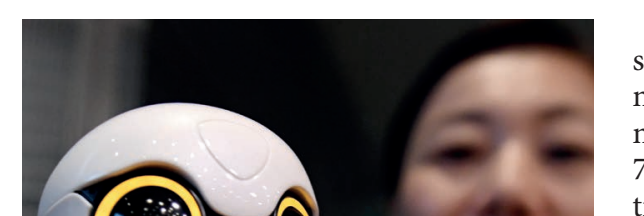

By contrast, corporate R\&D has recovered from the hit. According to the government thinktank National Institute of Science and Technology Policy (NISTEP), corporate expenditure on R\&D in Japan was 13.7 trillion yen (US $\$ 120$ billion) in 2015, almost quadruple the amount spent by universities (3.64 trillion yen) and ten times that spent by public institutions (1.4 trillion yen).

Corporate Japan accounted for $72.3 \%$ of the country's total R\&D investment, outdone only by neighbouring South Korea's $77.5 \%$ and China's $76.8 \%$. When measured as a percentage of GDP, private sector R\&D spending reached $2.57 \%$ in Japan, second to South Korea, and well above that of China.

The biggest private-sector spenders on science and technology in Japan are companies with capital worth 10 billion yen (US\$90 million) or higher. They make up more than $70 \%$ of the corporate R\&D. The largest contributor in 2017 was Toyota Motor, with plans to spend 1 trillion yen (US\$9 billion) by the end of this fiscal year. A quarter of this investment (up from a fifth compared to last year) is earmarked for research into promising technologies, including artificial intelligence (AI),

Toyota employee displaying the company's new Al communication robot 'Kirobo Mini'. 
Hamamatsu Photonics has a 90 per cent global market share in high-precision light sensors known as photomultipliers. Its stock price has jumped more than four-fold since 2009. 


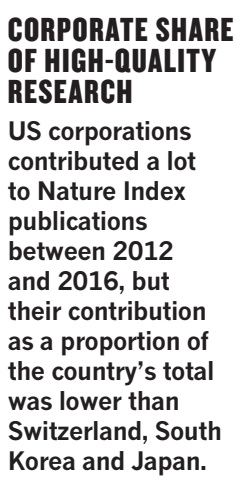

SPENDING VS OUTPUT

The Japanese corporations that produced the most high-quality research in the Nature Index between 2012 and 2016 didn't necessarily spend the most on research and development in 2016.
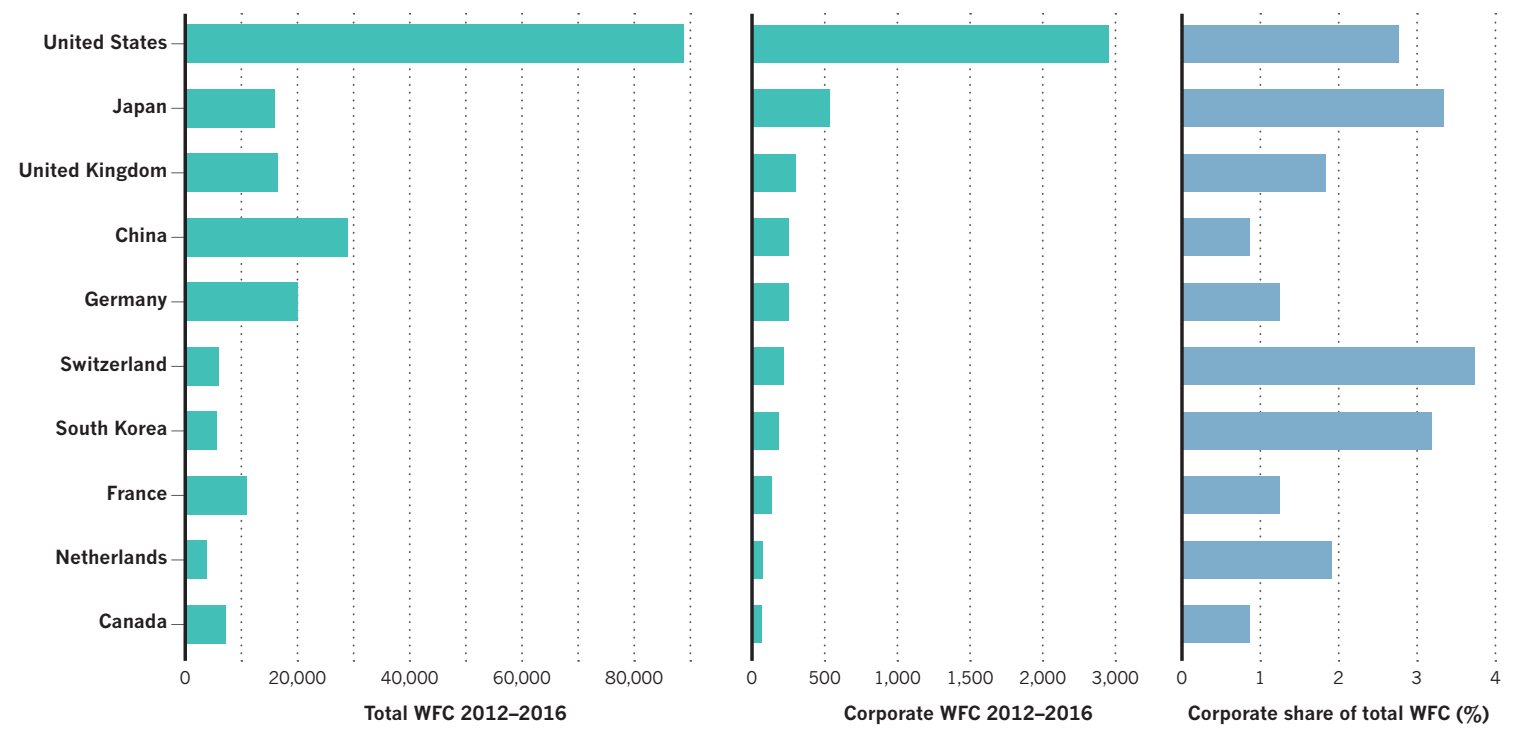

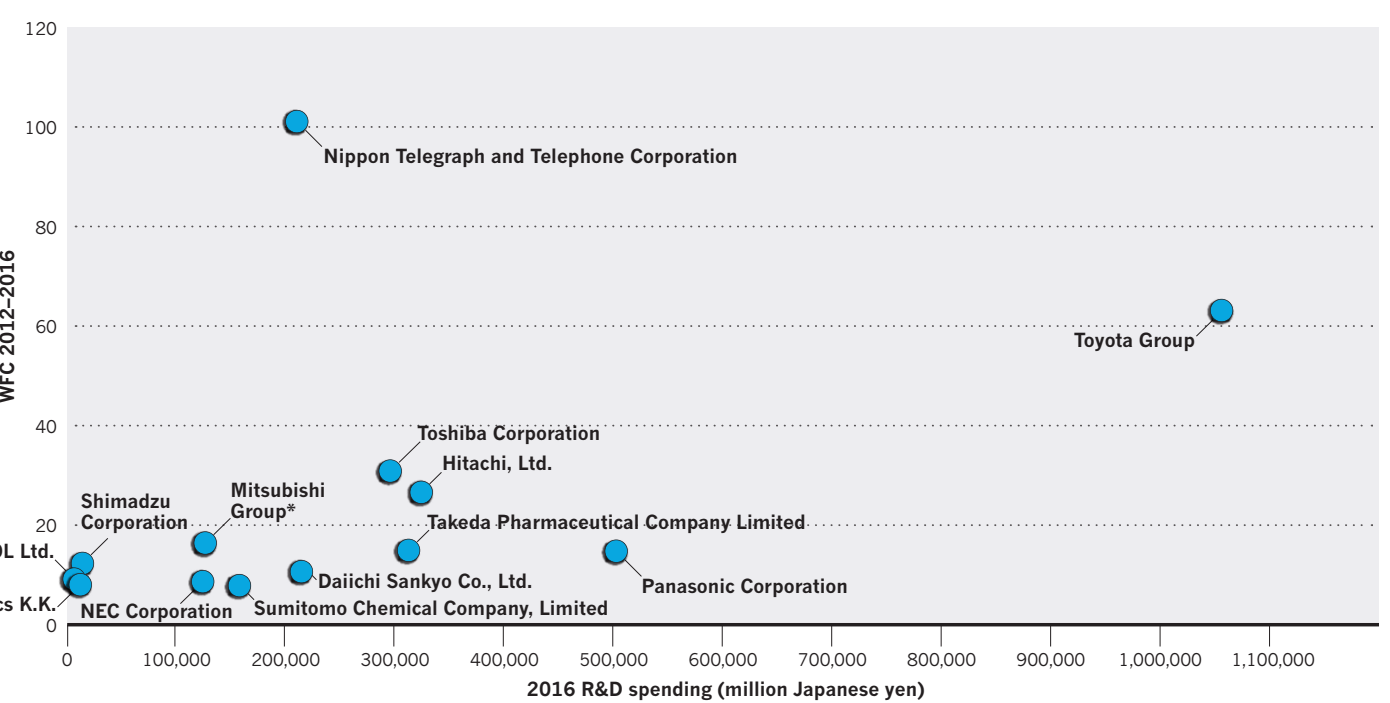

*R\&D output for Mitsubishi Group only includes spending by Mitsubishi Chemical. the company signed a contract to pay 1 billion yen (US\$9 million), every year, for 10 years, to the Osaka University Immunology Frontier Research Center (IFReC), led by immunologist, Shizuo Akira, who was the world's most highly cited scientist in 2006 and 2007, according to Thomson Reuters.

"These collaborations can bring merits for both sides," says Kumiko Miyazaki, whose research at the Tokyo Institute of Technology looks at strategic management of technologies. "Companies can learn from talented young researchers at universities, while universities can expand the scale of their research amid tight budgets from the government."

\section{TWO SIDES OF A COIN}

Increased reliance on corporations, however, will not necessarily translate into high scientific output. "Companies don't put so much weight on writing papers," says Miyazaki.

Companies that spend a lot on R\&D are not always the ones that publish a lot of papers in the high-quality journals tracked by the index. The telecommunications company Nippon Telegraph and Telephone Corporation Group (NTT), for example, is the largest corporate contributor to index authorship in Japan, but its R\&D expenditure is only about a fifth of Toyota's, at 210 billion yen (US $\$ 2$ billion) in 2017. According to the public relations office at NTT, the company sees papers published in high-impact journals as "very important as one subjective measure to evaluate our research strength, and a good motivation for authors."

The optical equipment manufacturer, Hamamatsu Photonics K.K., is also among the 14 Japanese companies ranked in the global top 100 corporations in the Nature Index in 2012-2016, despite an $\mathrm{R} \& \mathrm{D}$ expenditure this year of a mere 12.4 billion yen (US $\$ 100$ million). The director of Hamamatsu's central research laboratory, Tsutomu Hara, says papers published in highimpact journals are good for the company's image, and the company provides a small monetary bonus to researchers who publish papers.
However, Hara says, "as a private corporation, we put more focus on filing patents."

Honda Motor, whose R\&D expenditure was 750 billion yen (US\$6.6 billion) in 2017 - more than triple the amount spent by NTT Group - did not make the list of top 100 companies in the index in 2012-2016.

"The importance placed on publishing in high-impact journals depends on the company and the sector," Miyazaki explains. "In the case of component makers, publications contribute to marketing their products to their customers. But, a buyer would not consider publications to be an important criteria in buying a car."

Yamaguchi at Chiba adds that many Japanese companies still place more importance on submitting papers to Japanese-language journals and technical journals, which are not represented in the index. Corporate culture also matters, he says. "Companies that allow flexibility in research activities seem to appear more in high-impact journals, even though their R\&D expenditure is modest." 